\title{
PATTERN OF CLINICAL AND HEMATOLOGICAL PROFILE IN PATIENTS DIAGNOSED AS MEGALOBLASTIC ANEMIA IN A TERTIARY CARE CENTRE.
}

1. MBBS, M.Phil (Hematology) Assistant Professor Department of Pathology Khyber Medical College, Peshawar.

2. MBBS, M.Phil (Hematology)

Assistant Professor Department of Pathology

Khyber Medical College, Peshawar.

3. $4^{\mathrm{TH}}$ Year MBBS Student

Federal Medical and Dental College, Islamabad.

Correspondence Address: Dr. Muhammad Ihtesham Khan House No.502, Street 5, Sector F-8, Phase 6, Hayatabad. Ihteshamkhan9@yahoo.com

Article received on: $17 / 05 / 2018$

Accepted for publication: $31 / 08 / 2018$

Received after proof reading: $22 / 05 / 2019$

\begin{abstract}
Muhammad Ihtesham Khan ${ }^{1}$, Asif Hussain Munir², Syeda Hina Fatima ${ }^{3}$
\end{abstract}
ABSTRACT... To determine the pattern of clinical presentation, pattern of cytopenias, and haematological parameters of megaloblastic anemia in our setup. Study Design: Cross Sectional Descriptive study. Setting: Pathology Department, Khyber Teaching Hospital, Peshawar. Period: January 2016 to December 2016 (one year period). Materials and Methods: A total of 337 patients underwent bone marrow biopsy during the study period, out of which 46 patients were diagnosed as having megaloblastic anemia on bone marrow aspirate and B12 levels. The clinical features and hematological parameters of these patients were recorded in a proforma and the results were drawn accordingly. All cell counts were done on automated counter machine. Results: Out of 337 patients referred to pathology department for bone marrow aspiration, about 45 cases had megaloblastic anemia. These 45 cases were included in the study. Age of the study sample ranged from 1 year to 90 years (mean 32.2 years $\pm 12.1 \mathrm{SD}$ ). There were $35(78 \%)$ males and $10(22 \%)$ females, with male to female ratio of 3.5:1. Commonest clinical feature was generalized weakness and loose motion, while commonest physical sign was pallor, which were seen in $36(80 \%), 36(80 \%)$ and 40 $(88 \%)$ cases respectively. About $28(62 \%)$ patients had pancytopenia, $9(20 \%)$ patients had bicytopenia (low hemoglobin and platelet count), and $8(18 \%)$ cases had isolated anemia. Low $\mathrm{Hb}$ was present in all the $45(100 \%)$ patients. Both the mean hemoglobin level and platelet count were reduced $\left(7.4 \mathrm{~g} / \mathrm{dL}\right.$ and $128 \times 10^{9} / \mathrm{L}$. respectively) while mean white cell count in study sample was normal (mean 5.0×10\%/L). Conclusion: Megaloblastic anemia may presents as anemia, bicytopenia or pancytopenia. The cytopenias are important feature of megaloblastic anemia. Generalized weakness, and lethargy are the common clinical presentation, while pallor is common physical finding. Patients presenting with a constellation of generalized weakness, pallor and pancytopenia should be suspected of megaloblastic anemia and should be investigated accordingly.

Key words: Bicytopenia, Bone Marrow Biopsy, Haematological Parameters, Megaloblastic Anemia, Pallor, Pancytopenia.

Article Citation: Khan MI, Munir AH, Fatima SH. Pattern of clinical and hematological profile in patients diagnosed as megaloblastic anemia in a tertiary care centre. Professional Med J 2019; 26(6):934-938.

DOI: $10.29309 / T P M J / 2019.26 .05 .3600$

\section{INTRODUCTION}

Megaloblastic anemia is a hematological disorder due to vitamin B 12 and folate deficiency. ${ }^{1-7}$ It is characterized by impairment of the DNA synthesis in the bone marrow haematopoietic cells. ${ }^{1-7}$ It is associated with macrocytic anemia and megaloblastic changes in the erythroid cells of the bone marrow. ${ }^{8,9}$ The presence of megaloblasts in the bone marrow is diagnostic of the disease. ${ }^{10}$

Megaloblasts are large red cell precursors in which maturation of nucleus is delayed as compared to the cytoplasm. ${ }^{10}$ These cells were termed as Megaloblasts by Ehrilich in 1880. ${ }^{10}$

Megaloblastic anemia is caused due to vitamin B-12 and folate deficiency. ${ }^{1}$ Conditions that cause vitamin B12 deficiency include chronic diarrhea causing malabsorption syndromes, intestinal worms, surgery of ileum, and cytotoxic drugs, anticonvulsants, proton pump inhibitors, prolong antibiotic use and alcohol intake. ${ }^{2}$

The clinical presentation of patients with megaloblastic anemia ranges from asymptomatic 
disease to life-threatening infections. ${ }^{3,5,11}$ Patients usually present with slow onset pallor, lethargy, weakness and later on respiratory and urinary tract infections. ${ }^{2}$ On examination, patients have beefy red tongue which is characteristic of the disease. ${ }^{2}$ There is history of weight loss and anorexia. $^{2}$

There may be recurrent episodes of diarrhea due to epithelial changes in the gastrointestinal tract. ${ }^{2}$ Bruises and purpura on skin are present due to low platelet count. ${ }^{2}$ Neurological symptoms may be seen in cases with severe vitamin B 12 deficiency. ${ }^{2}$ The neurological features include peripheral neuropathy, gait abnormality, dementia and mental changes. ${ }^{2,3}$ Infants may also develop megaloblasstic anemia. ${ }^{2,6}$ Infants who are breastfed by mother who is a strict vegetarian have higher risk of developing megaloblastic anemia. ${ }^{2,6}$

The laboratory findings in patients of megaloblastic anemia include a raised mean corpuscular volume above 95 femtolitre. ${ }^{7,12}$ Blood counts may show cytopenias i.e bicytopenia, pancytopenia or isolated anemia. ${ }^{2}$ The levels of serum B 12 and folate are reduced in such patients. ${ }^{4-7}$ Blood film shows hypersegmented neutrophils and macro-ovalocytosis. ${ }^{2,7,12}$ Bone marrow biopsy is necessary for diagnosis of megaloblastic anemia. ${ }^{17,12,13}$ Bone marrow shows characteristic megaloblasts and giant metamyelocyes. ${ }^{2,12}$

The present study was done to determine the pattern of clinical and hematologic profile of patients with megaloblastic anemia in our setup.

\section{OBJECTIVE}

The objective of the study was to determine the pattern of clinical presentation, pattern of cytopenias, and haematological parameters of megaloblastic anemia in our setup.

\section{Study Design}

It was a Cross Sectional Descriptive study.

\section{Setting}

The study was done in Pathology Department, Khyber Teaching Hospital, Peshawar.

\section{Duration}

The study was done from January 2016 to December 2016 (i.e one year period)

\section{Sampling Technique}

Sampling was done by Non probability purposive sampling.

\section{Inclusion Criteria}

All patients diagnosed on bone marrow aspiration as megaloblastic anemia were included in the study. Diagnosis was made through bone marrow aspiration examination and B12 levels.

\section{Exclusion Criteria}

Patients whose aspirate samples were inadequate for comment were excluded from the study.

\section{Procedure}

Bone marrow examination was performed by using Jamshidi bone marrow biopsy needle, and the aspirate was examined for metamyelocytes, megaloblasts, and reported by the pathologist. B 12 levels were determined and were found to be low in all cases. Clinical presentation, physical findings, and hematological parameters like Hemoglobin ( $\mathrm{Hb})$, total leukocyte count (TLC), platelet count, mean cell volume (MCV), mean corpuscular hemoglobin $(\mathrm{MCH})$, mean cell hemoglobin concentration (MCHC) were noted in proforma and results were drawn accordingly.

\section{RESULTS}

A total of 337 patients underwent bone marrow biopsy during the study period, out of which 46 patients were diagnosed as having megaloblastic anemia on bone marrow aspirate. The age of the study sample ranged from 1 year to 90 years, with mean of $32.2 \pm 12.1 \mathrm{SD}$. Out of 46 cases, about $35(78 \%)$ cases were male and $10(22 \%)$ cases were females. Male to female ratio was 3.5:1.

Chief complaints and physical signs of the study sample are shown in Table-l. Pattern of cytopenias are shown in Table-II. Hematological parameters as per Automated hematology analyzer are show in Table-III. 


\begin{tabular}{|c|c|c|}
\hline Chief Complaints & \multicolumn{2}{|c|}{ n (\%) } \\
\hline Generalized weakness & \multicolumn{2}{|c|}{$36(80 \%)$} \\
\hline Loose motion & \multicolumn{2}{|c|}{$36(80 \%)$} \\
\hline Lethargy & \multicolumn{2}{|c|}{$29(65 \%)$} \\
\hline Generalized body aches & \multicolumn{2}{|c|}{$10(22 \%)$} \\
\hline Shortness of breath & \multicolumn{2}{|c|}{$10(22 \%)$} \\
\hline Anorexia & \multicolumn{2}{|c|}{$3(7 \%)$} \\
\hline \multicolumn{3}{|l|}{ Physical findings } \\
\hline Pallor & \multicolumn{2}{|c|}{$40(88 \%)$} \\
\hline Jaundice & \multicolumn{2}{|c|}{$3(6 \%)$} \\
\hline Petechiae & \multicolumn{2}{|c|}{$6(13 \%)$} \\
\hline Fever & \multicolumn{2}{|c|}{$7(15 \%)$} \\
\hline \multicolumn{3}{|c|}{$\begin{array}{c}\text { Table-I. Clinical features and physical findings in } 45 \\
\text { patients of megaloblastic anemia }\end{array}$} \\
\hline \multicolumn{2}{|l|}{ Cytopenias } & n (\%) \\
\hline \multicolumn{2}{|c|}{ Isolated Anemia(decreased $\mathrm{Hb}$ ) } & $8(18 \%)$ \\
\hline \multicolumn{2}{|c|}{ Bicytopenia (decreased $\mathrm{Hb}$ and platelers) } & $9(20 \%)$ \\
\hline \multicolumn{2}{|c|}{ Pancytopenia } & $28(62 \%)$ \\
\hline \multicolumn{3}{|c|}{$\begin{array}{c}\text { Table-II. Distribution of cytopenias in } 45 \text { cases of } \\
\text { megaloblastic anemia }\end{array}$} \\
\hline Hematological Parameters & Range & Mean \pm SD \\
\hline Haemoglobin (g/dL) & $5-12$ & $7.4 \pm 2.5$ \\
\hline Total Leukocyte Count (10\%/L) & $1.5-19$ & $5.0 \pm 1.5$ \\
\hline Platelet count $\left(10^{9} / \mathrm{L}\right)$ & $1-464$ & $128 \pm 64$ \\
\hline Mean Cell Volume (fL) & $61-136$ & $92 \pm 12$ \\
\hline Mean Cell Hemoglobin (gm/dL) & $32-35$ & $33 \pm 4.5$ \\
\hline $\begin{array}{l}\text { Mean Cell Hemoglobin } \\
\text { Concentration }(\mathrm{gm} / \mathrm{dL})\end{array}$ & $22-34$ & $34 \pm 3.3$ \\
\hline \multicolumn{3}{|c|}{$\begin{array}{l}\text { Table-III. Hematological parameters in } 45 \text { patients of } \\
\text { mealoblastic anemia. }\end{array}$} \\
\hline
\end{tabular}

\section{DISCUSSION}

Megaloblastic anemia is a non-malignant hematological disorder in which there is defect in DNA synthesis in hematpoietic cells of the bone marrow. ${ }^{1}$ Macrocytosis and cytopenias are common features of megaloblastic anemia. ${ }^{1}$ Underlying cause of megaloblastic anemia is vitamin B-12 deficiency. ${ }^{14}$ Parasitic infections like Diphyllobothrium latum (Fish tapeworm), vegetarianism, gastrectomy, drugs like oral contraceptives and anticonvulsants and alcoholism are common causes of vitamin B 12 deficiency. ${ }^{14}$ Food of animal origin is the main source of vitamin B-12. ${ }^{2}$ Absence of intrinsic factor secondary to gastrectomy and pernicious anemia lead to malabsorption of vitamin B 12 and thus megaloblastic anemia. ${ }^{2}$

Megaloblastic change on bone marrow aspirate and decreased serum vitamin B 12 level are diagnostic of megaloblastic anemia. ${ }^{2}$ Studies have been done in which bone marrow aspirate was used to confirm diagnosis of megaloblastic anemia. ${ }^{2,11}$ In the present study, bone marrow aspiration was used to diagnose megaloblastic anemia. Nuclei of megaloblasts are larger than normoblasts, and their chromatin is dispersed. ${ }^{2}$ Giant metamyelocytes are typical of megaloblastic anemia. $^{2}$

In the present study, megaloblastic anemia was common in males as compared to females. In a study done by Momin M and colleagues in 2017, megaloblastic anemia was commonly seen in males as compared to females. ${ }^{1}$ Similar findings are reported by two different studies done by Charke $\mathrm{K}$ and Baik W. ${ }^{15,16}$ Reason for this may be the fact that males have more access to health care centres as compared to females in our setup.

In the present study, generalized weakness and loose motion were the commonest complaints, while pallor was the commonest physical sign seen in 36 (80\%), 36 (80\%) and 40 (88\%) cases respectively. In a study done by Yallinedi $S$ and colleagues in 2016, all the patients (100\%) presented with generalized weakness, and all had pallor. ${ }^{11}$ In a study done by Momin $\mathrm{M}$ and colleagues in 2017, it was seen that the most common complaint was generalised weakness, followed by fever, shortness of breath and anorexia, while common clinical finding was pallor. ${ }^{1}$ Similar findings were showed by other studies done by Yallinedi $S$ and Zangin E. ${ }^{11,17}$ In our study, no case had neurological manifestation, but Faruk I has reported a very high incidence of $33 \%$ in his study. ${ }^{18}$ In another study done by Yallenedi $S$ and colleagues in 2016 , about $38 \%$ patients showed neurological deficits. ${ }^{11}$ Early referral for workup of anemia and timely management of such cases may be the reason for low incidence of neurological deficit in our setup.

In our study, about $8(18 \%)$ cases had isolated anemia, 9 (20\%) cases had bicytopenia (low hemoglobin and platelet count) while 28 (62\%) case had pancytopenia. In a study done by Momin $M$ and colleagues in 2017 , about $52.5 \%$ cases had 
pancytopenia, and was the common cytopenia. ${ }^{1}$ Pancytopenia was dominant cytopenia in two other studies done by Hirach and and Hamid. ${ }^{19,20}$ On the contrary, Meghann $\mathrm{P}$ showed that bicytopenia was present in $78 \%$ of cases and was the dominant cytopenia. ${ }^{21}$ In another study done by Yallenidi $S$ and colleagues in 2016, about $78 \%$ cases had bicytopenia and was the commonest cytopenia in the study sample. ${ }^{11}$ It is suggested that as severity of the disease increases, there develops thrombocytopenia , and this is followed by pancytopenia. ${ }^{1}$

The mean hemoglobin in the present study was $7.4 \mathrm{~g} / \mathrm{dL}$, mean MCV was $92 \mathrm{fL}$. In a study done by Yallenidis $S$ and colleagues in 2016, the mean hemoglobin was $7 \mathrm{~g} / \mathrm{Dl} .{ }^{11}$ In a study done by Momin $\mathrm{M}$ in 2017, the mean hemoglobin was $6 \mathrm{~g} / \mathrm{dL} .{ }^{1}$ Yallenidi $\mathrm{S}$ and Zenign $\mathrm{E}$ and also reported mean $\mathrm{Hb}$ of $6 \mathrm{~g} / \mathrm{dL} .{ }^{11,17}$ Raised mean cell volume is an early diagnostic indicator of Vitamin B12 deficiency, regardeless of hemoglobin concentration. ${ }^{1,6,14}$

The present study describes the wide spectrum of clinical and hematological features with which megaloblastic patients present in our setup. The patients presenting with generalized weakness and pancytopenia should be worked up for megaloblastic anemia as it is easily treatable by supplements.

\section{CONCLUSION}

The study shows that megaloblastic anemia is common in males as compared to females in our setup. Commonest clinical feature is generalized weakness, loose motion, and pallor. Commonest cytopenia is pancytopenia, followed by bicytopenia. So, patients with megaloblastic anemia present with constellation of loose motion, generalized weakness, pallor and pancytopenia in our setup. Pimary health care physicians should be aware of these patterns with which patients in our setup present.

Copyright@ 31 Aug, 2018.

\section{REFERENCES}

1. Momin M, Reddy KM, Prusty SK, Aluri A. Clinical, haematological and bone marrow aspiration evaluation in Megaloblastic anemia - study of 80 cases in a tertiary care hospital. Telangana. Int. J. Curr. Res. Biol. Med.2017; 2(8): 1-7.

2. Srikanth S. Megaloblastic anemia - A clinical spectrum and a hematological profile: The day-to-day public health problem. Med J DY Patil Univ 2016; 9(3):307-10.

3. Sally S. Clinical practice: Vitamin B12 deficiency. New Eng J Med. 2013; 368:149-60.

4. Sarah D, Veronica HF, Julie P, Paul S, Amanda B. Vitamin B12 deficiency: The great masquerader. Pediatric Blood Cancer. 2014; 61:753-5.

5. Siddiqui B, Rabindranath D, Faridi SH, Khan A, Haiyat S, Eswaran R. Megaloblastic anemia: A common but often neglected cause of pyrexia of unknown origin. J TransI Int Med. 2015; 3(2): 64-7.

6. Mussarrat N, Razeq F, Khan MT. Clinical and hematological features of megaloblastic anemia alone or in combination with iron deficiency anemia- an analysis of 349 patients. J Med Sci. 2009; 17(2):81-84.

7. Kannan A, Tilak V, Rai M, Gupta V. Evaluation of clinical, biochemical and hematological parameters in macrocytic anemia. Int J Res Med Sci 2016; 4:26708.

8. Michael W, David R, Cooper B. Megaloblastic anemia. Nathan and Oski's hematology of infancy and childhood 7th edition Saunders. 2014:419-21

9. Norma BL. Megaloblastic anemia. Nelson textbook of pediatrics 20th edition. Elsevier. 2015:2319-21.

10. Ehrlich P. Hematological profile of megaloblastic anemia. Indian Pediatrics. 1980; 35:55-8.

11. Yellinedi S, Karanam S, Gowdar G. Clinico-hematologic profile of megaloblastic anemia in children. Int $\mathrm{J}$ Contemp Pediatr. 2016; 3:28-30.

12. Buttarello M. Laboratory diagnosis of anemia: Are the old and new red cell parameters useful in classification and treatment, how?. Int J Lab Hem. 2016, 38 (1), 123-32.

13. Jaswal TS, Mehta HC, Gupta V, Singh M, Singh S. Serum lactate dehydrogenase in diagnosis of megaloblastic anaemia. Indian J Pathol Microbiol. 2000; 43(3):325-9.

14. Khanduri U,Sharma A, Joshi A. Occult cobalamin and folate deficiency in Indians. Nat Med J India.2005; 18:182-3. 
15. Charke K. Vitamin B12 and folic acid deficiency in late life age. Indian J Pathol Microbiol. 2004; 33:34-41.

16. Baik W, Russell M. Vitamin B-12 deficiency in elderly. Annu Rev Nutr. 1999; 19:357-77.

17. Zengin E, Sarper N. Clinical manifestations of infants with nutritional vitamin B12 deficiency due to maternal dietary deficiency. Acta Pediatrica. 2009; 9:98-102.

18. Faruk I, Ozlem M,Altunbasak S, Goksel L. Neurologic findings of nutritional vitamin B12 deficiency in children. Turk J Pediatric. 2010; 52:17-21.
19. Hirachand S. Clinico hematological profile in megaloblastic anemia. J Inst Med. 2014; 36:1.

20. Hamid GA. Pattern of pancytopenia in Yemen. Turk J Hematol 2008; 25:71-74.

21. Meghann P, Andrew W. Pancytopenia in hospitalized children a five-year review. J Pediatr Hem Oncol. 2010; 32(5):e192-4.

\begin{tabular}{|c|l|l|l|}
\hline \multicolumn{3}{|c}{ AUTHORSHIP AND CONTRIBUTION DECLARATION } \\
\hline Sr. \# & \multicolumn{1}{|c|}{ Author-s Full Name } & \multicolumn{1}{|c|}{ Contribution to the paper } & Author=s Signature \\
\hline 1 & M. Ihtesham Khan & $\begin{array}{l}\text { Principle Author, Material \& } \\
\text { Method. } \\
\text { Discussion, Review, Result } \\
\text { complication. }\end{array}$ \\
\hline 3 & Asif Hussain Munir & Syeda Hina Fatima & Aj \\
\hline
\end{tabular}

